\title{
MONITORAMENTO E INTERPRETAÇÃO DA QUALIDADE DO AR PARA MATERIAL PARTICULADO NA ÁREA DE INFLUÊNCIA DO ATERRO SANITÁRIO DE BELO HORIZONTE
}

\author{
Leonardo de Salles ${ }^{1} \&$ Danielle Piuzana ${ }^{2}$
}

\begin{abstract}
RESUMO
A poluição atmosférica tem aumentado devido aos processos de industrialização e urbanização acelerada. A má qualidade do ar tem causado sérios problemas à saúde da população, ao meio ambiente e aos materiais. O monitoramento da qualidade do ar na área de influência do Aterro Sanitário de Belo Horizonte tem como objetivo determinar as concentrações de Partículas Inaláveis - PI e Partículas Totais em Suspensão (PTS) por meio de amostradores PM 10 e de Grande volume (AGV -Hi Vol) respectivamente, em dois pontos distintos escolhidos segundo a direção predominante dos ventos e pelo período de um ano. Os resultados do monitoramento indicam que no ponto I, na porção sudeste do empreendimento, tanto as concentrações de PI e PTS se mantiveram inferiores aos limites estabelecidos pelasleis brasileiras enquanto no ponto II, à noroeste do empreendimento as concentrações das partículas ultrapassaram os valores de referência de padrão primário por seis vezes no período das medições. Os dados excedentes foram obtidos no período de seca.

Palavras-chave: material particulado, emissões atmosféricas, qualidade do ar
\end{abstract}

\section{INTRODUÇÃO}

A poluição atmosférica é considerada um dos tipos de poluição de extrema complexidade. Está relacionada ao crescimento humano e aos próprios avanços que a humanidade vem alcançando, quando se agruparam em locais chamados de centro urbanos. Nestes locais acorrem as maiorias de emissões de gases e material particulado responsáveis pela denominada "poluição cega" e por isso, cada vez mais estudos da qualidade do ar vêm sendo desenvolvidos seja em grandes centros urbanos (CPRH, 1998), seja em empreendimentos considerados de grande potencial poluidor (Almeida, 1999; Jacomino et al. 2002). As principais fontes da poluição atmosférica são as indústrias e os inúmeros veículos automotivos que eliminam os principais gases poluidores, como o monóxido de carbono $(\mathrm{CO})$, dióxido de enxofre $\left(\mathrm{SO}_{2}\right)$, óxido de nitrogênio $\left(\mathrm{NO}_{\mathrm{x}}\right)$, material particulado (MP) dentre outros.

O material particulado é uma mistura de partículas líquidas e sólidas em suspensão no ar. Sua composição depende das fontes de emissão. As partículas podem ser divididas em dois grupos: (1) Partículas Totais em Suspensão-PTS, possuem diâmetro maior que $10 \mathrm{~mm}$ até $100 \mathrm{~mm}$, oriundas da combustão descontrolada, movimentação do solo ou outros minerais da crosta terrestre. Estas partículas podem conter silício, titânio, alumínio, ferro, sódio, cloro além de pólens, esporos e materiais orgânicos; (2) Partículas Inaláveis - PI, possuem menos que $10 \mathrm{~mm}$ de diâmetro, derivadas da queima dos combustíveis usados nas indústrias e veículos automotores. Estas partículas podem ser formadas por carbono, chumbo, vanádio, bromo e os óxidos de enxofre e nitrogênio.

Este material particulado podem atingir as porções inferiores do trato respiratório, prejudicando as trocas gasosas, alem de estarem relacionados com as alergias, asma e bronquite crônica, podendo causar também, irritação na garganta e ser responsável pela diminuição da resistência às infecções. As partículas com tamanhos menores que 2,5 mm em diâmetro causam severos danos à saúde e o material particulado diminui a visibilidade (CPRH, 1998). A presença de material particulado na atmosfera provoca o aumento da turbidez do ar, o que causa redução da visibilidade, além de provocar sujeira nas superfícies de casas e edifícios, móveis e objetos e, muitas vezes, sua erosão.

Este trabalho apresenta dados de monitoramento para determinação de concentrações de Partículas Totais em Suspensão (PTS) e Partículas Inaláveis (PI) por Amostradores de Grandes Volumes (AGV Hi-Vol) e PM10, respectivamente, no entorno do Aterro Sanitário de Belo Horizonte. A opção por este tema é justificada por se tratar de um depósito de lixo, cujo fluxo de veículos de carga e movimentação de solo é muito grande. Neste trabalho foram abordados os tipos de poluição atmosférica, os gases que a compõe e os possíveis males causados por cada um deles à saúde 
humana. Os resultados obtidos no monitoramento, são comparados com a legislação vigente a fim de identificar o índice de contribuição de poluentes, e a partir destes, propor alternativas para a diminuição da poluição atmosférica.

\section{LOCALIZAÇÃO E DADOS GERAIS DOATERRO SANITÁRIODE BELOHORIZONTE}

A área estudada está localizada ao lado da BR-040, km 2, sentido Belo Horizonte - Brasília, na Regional Noroeste do município de Belo Horizonte (Figura 1), próximo ao limite com o Município de Contagem.

De acordo com as informações fornecidas pelo Sistema de Limpeza Urbana - SLU, o aterro sanitário possui uma área de 132 ha (ver Figura 2 e Figura 3), tendo iniciado operação em 1973. Na década de 80 houve surgimento de bairros no entorno do aterro, sendo os mais importantes: Dom Bosco, Califórnia, Pindorama, Filadélfia, Glória e Álvaro Camargos. O aterro caracterizava-se, até 1997, por 4 bacias de disposição de lixo. A partir de então houve a implantação do Projeto de Biorremediação cujo principal objetivo é aumentar a velocidade da degradação do lixo por meio de bactérias de alta resistência e com grande capacidade de transformação da celulose.

Todo o lixo coletado no município de Belo Horizonte é atualmente disposto no Aterro Sanitário da BR-040. Segundo Sousa et al. 2002, para o ano de 1994, o Município de Belo Horizonte contava com uma população residente, acrescida da flutuante, de 2.500 .000 habitantes. Desse total, aproximadamente $85 \%$ da área era atendida pelo serviço de limpeza urbana. A produção média de lixo/dia era de 3.204,41 toneladas considerando os 92 dias do $4^{\circ}$ trimestre de 1994 . Atualmente a produção é superior a $4.300 t / d i a$.

O aterro sanitário localiza-se a norte do Quadrilátero Ferrífero, na parte noroeste da região metropolitana de Belo Horizonte. Encontra-se inserido na porção sul do Cráton do São Francisco, onde as rochas possuem idades arqueana e paleoproterozóica. Tais rochas compõem o embasamento gnáissico-migmatítico na área do aterro é constituído por rochas graníticas e granodioríticas, com bandamento grosseiro e apresentando feições migmatíticas com estruturas nebulíticas, estromáticas, schlieren, etc segundo Brandalise (1999). O complexo gnáissico-migmatítico na região foi denominado por Noce (1995) de Complexo Belo Horizonte, sendo constituído por gnaisses cinzentos freqüentemente com um bandamento composicional, feições de migmatização e integrantes de uma suíte do tipo Tonalito Throndjemito Gnaisse (TTG) que engloba parte dos municípios de Ravena, Traíras, General Carneiro e a zona metropolitana de Belo Horizonte.

Toda a região apresenta espesso manto de alteração, tendo como rocha de origem gnaisses de composição desde granítica a tonalítica. Esta associação do tipo de rocha/manto de intemperismo condiciona uma fragilidade morfológica, onde qualquer intervenção antrópica deverá apresentar um planejamento direcionado aos diversos processos erosivos e suas

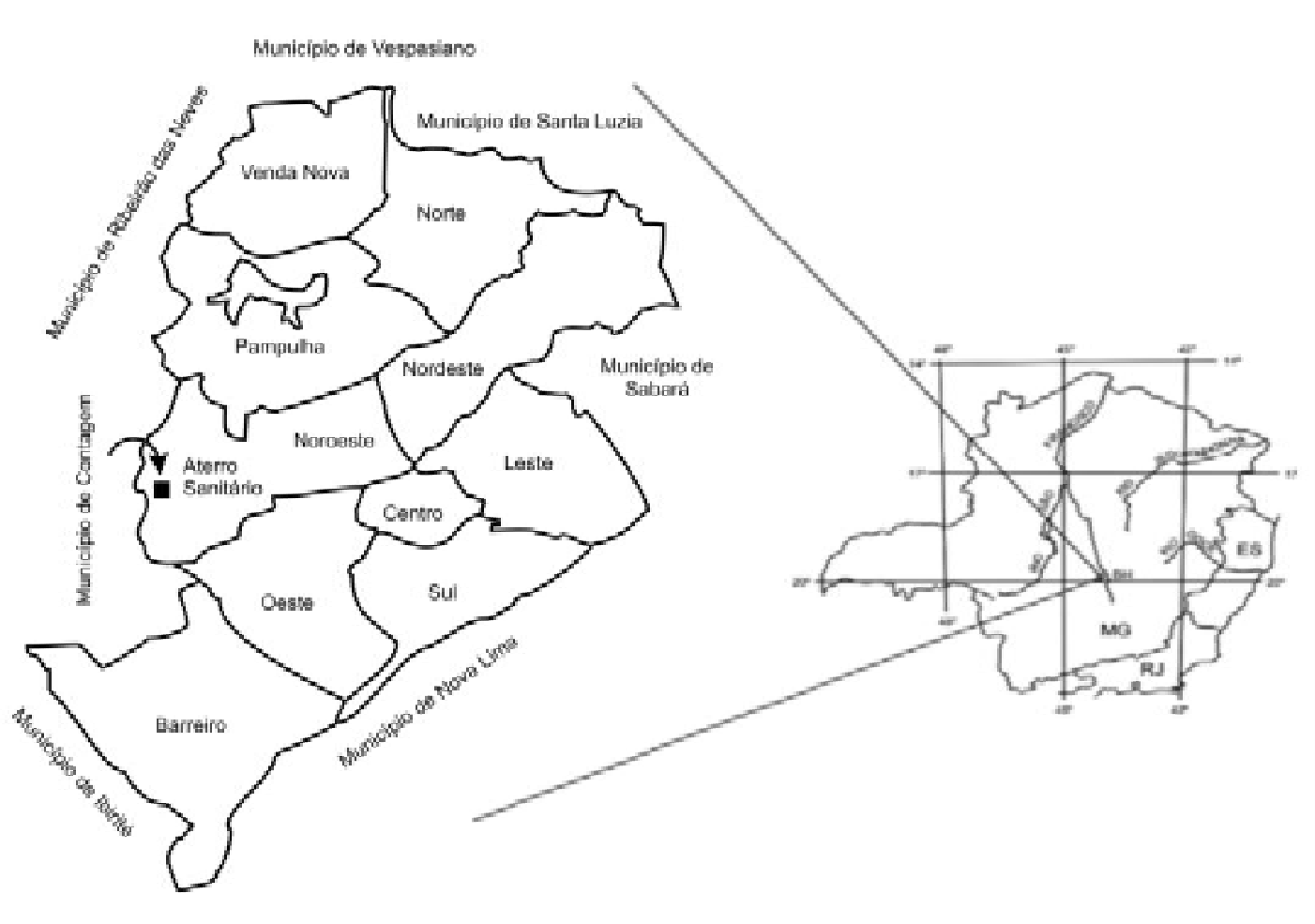

Figura 1 - Mapa do município de Belo Horizonte com a localização do Aterro Sanitário segundo Prefeitura Municipal de Belo Horizonte. Retirado de Sousa et al. 2002. 


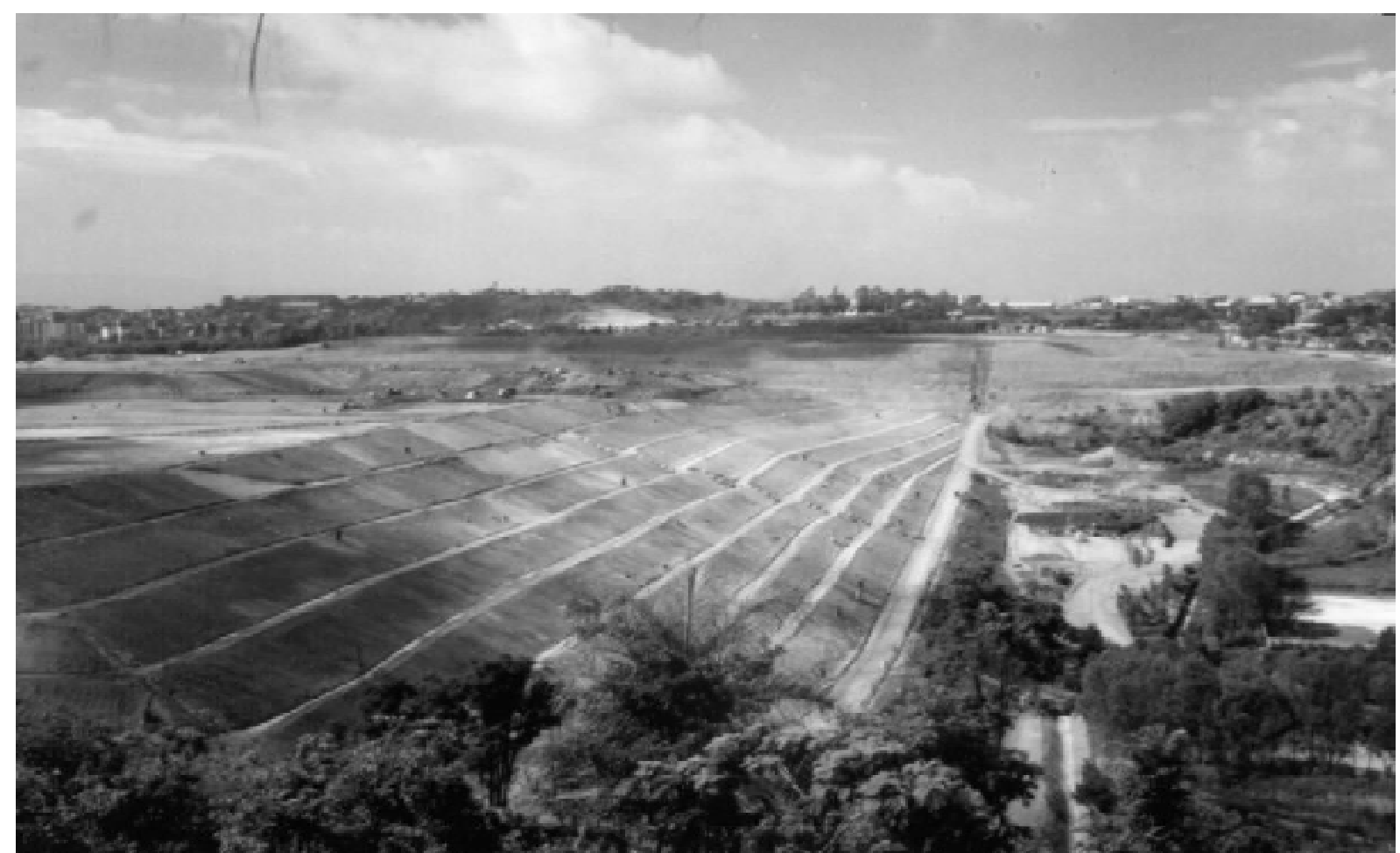

Figura 2 - Foto parcial do aterro sanitário vista do seu ponto mais alto.

consequiências, fato este hoje observado no processo de recuperação da Lagoa da Pampulha.Quanto à hidrogeologia, a região é importante na manutenção hídrica das bacias Pampulha e Arrudas, pertencentes à Bacia Hidrográfica Estadual do Rio das Velhas. Os tipos de aquíferos relacionados às rochas do Complexo Belo Horizonte são essencialmente aquíferos fraturados por se tratarem de rochas cristalinas ou maciças, praticamente impermeáveis e não porosas. O acúmulo de água se dá ao longo da fraturas e/ou diáclases (Silva et al. 1995).

\section{METODOLOGIA}

Determinou-se, durante o período entre junho de 2003 a junho de 2004, a concentração de Partículas Totais em Suspensão (PTS) e Partícula Inaláveis (PI).

Para a realização das coletas foram utilizados Amostradores de Grandes Volumes - AGV do tipo HiVol para a coleta de PTS e coletores de PI do tipo PM10. Além disso, foi utilizado um KIT de calibração do tipo CPV fabricado pela empresa Energética calibrado segundo DIAS (2001).

Tais equipamentos e calibrações foram realizados conforme as normas ABNT (Associação Brasileira de Normas Técnicas - NBR 9547/97) e metodologias da US EPA - United States Environment Protection Agency 40 CFR, Parte 50, Ap. B) aceitas por os órgãos de controle do País.

Para a instalação dos Amostradores PTS - Partículas Totais em Suspensão e PI - Partículas Inaláveis, foi considerada a direção predominante dos ventos, tendo como orientação as informações fornecidas pelo Instituto de Meteorologia - INMET $-5^{\circ}$ Distrito de
Meteorologia de Belo Horizonte e sua correlação com a planta baixa da região. A predominância dos ventos na região é no sentido Sudeste / Noroeste.

Os pontos de amostragens foram previamente indicados conforme mapa de localização do Aterro Sanitário (figura 3) e posição predominante dos ventos. Os pontos de amostragem foram posicionados conforme a seguinte disposição:

O Ponto I (figura 3) foram instalados os equipamentos Hi-Vol e PM10 à Sudeste, à montante do empreendimento, em relação à direção predominante dos ventos. Este ponto foi definido com objetivo de caracterizar a presença de PTS e PI na área de predominância residencial, em torno da Central de Tratamentos de Resíduos Sólidos - CTRS.

- O Ponto II (figura 3) foram instalados os equipamentos Hi-Vol e PM10 no quadrante Noroeste, à jusante do empreendimento, levando-se em consideração a posição predominante dos ventos. $\mathrm{O}$ Ponto II encontra-se em condições favoráveis a movimentação dos ventos, uma vez que se direcionam, após a passagem pelo aterro, à área residencial, podendo evidenciar os riscos de contaminação na área urbana após o empreendimento.

As coletas foram realizadas simultaneamente nos dois pontos de amostragens, a cada 06 (seis) dias, com duração de aproximadamente 24 (vinte e quatro) horas, buscando atender as condições mínimas definidas por norma de amostragem.

Para efeito de comparação e estudos dos resultados, foram adotados os limites descritos na Resolução CONAMA 03 de 28/06/90 e Deliberação Normativa COPAM 01 de 26/05/81. 


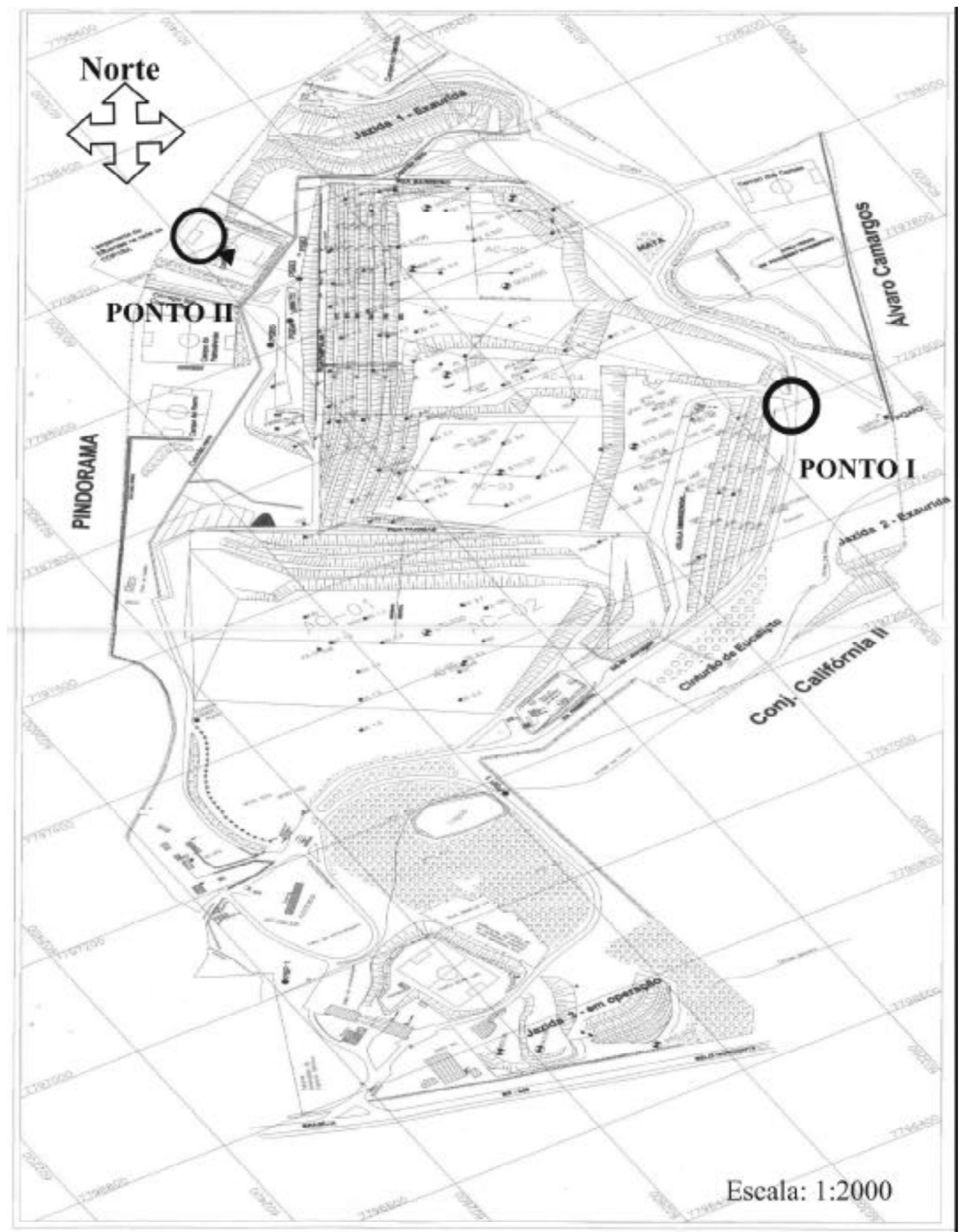

Figura 3 - Levantamento Planialtimérico Cadastral do Aterro Sanitário, contendo demarcação dos pontos de monitoramento (Ponto I e Ponto II). Fonte: Prefeitura Municipal de Belo Horizonte (2002)

\section{RESULTADOS E DISCUSSÕES}

\section{Monitoramento das Partículas Inaláveis - PI e Partículas totais em Supensão PTS}

A Tabela 1 apresenta o número de amostragem em cada ponto, valores mínimos e máximos para cada tipo de partículas e a média aritmética anual. Os dados completos de monitoramento das Partículas Inaláveis - PI e Partículas totais em Supensão - PTS obtidos encontra-se nos Anexos 1 e 2 respectivamente. Em cada anexo encontram-se os dados dos pontos de amostragem I e II.
Considerando os limites estabelecidos pela Resolução CONAMA 03/90 no qual a Concentração Máxima Diária de Partículas Inaláveis - PI, permitida para

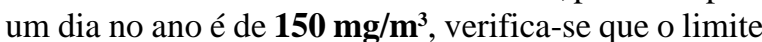
estabelecido não foi ultrapassado em nenhum dos pontos avaliados comparado aos valores avaliados no período 20 de Junho de 2003 a 08 de Junho de 2004. Já a Concentração Máxima Diária de Partículas Totais em Suspensão - PTS, permitida para um dia no ano que é de $\mathbf{2 4 0} \mathbf{m g} / \mathbf{m}^{3}$, comparado aos valores avaliados no período acima mencionado, verifica-se que o limite estabelecido foi ultrapassado em 01 (um) dia no PONTO I e em 06 (seis) dias no pontos PONTO II. 
Tabela 1- Quadro Resumo do Monitoramento das Partículas Inaláveis - PI e Partículas totais em Suspensão - PTS

\section{PI - Partículas Inaláveis}

\begin{tabular}{|c|c|c|c|c|c|}
\hline Ponto & $\begin{array}{l}\text { Número de } \\
\text { amostragens }\end{array}$ & $\begin{array}{c}\text { Mínimo } \\
\left(\mu \mathrm{g} / \mathrm{m}^{3} \mathrm{P}\right)\end{array}$ & $\begin{array}{l}\text { Máximo } \\
\left(\mu \mathrm{g} / \mathrm{m}^{3} \mathrm{P}\right)\end{array}$ & $\begin{array}{c}\text { MAA } \\
\left(\mu \mathrm{g} / \mathrm{m}^{3} \mathrm{P}\right)\end{array}$ & $\mathrm{NE}^{* *}$ \\
\hline \multicolumn{6}{|l|}{ PONTO - I } \\
\hline PONTO - II & 55 & 9,85 & 124,12 & 44,47 & 00 \\
\hline
\end{tabular}

\section{PTS - Partículas Totais em Suspensão}

\begin{tabular}{cccccc}
\hline \hline Ponto & $\begin{array}{c}\text { Número de } \\
\text { amostragens }\end{array}$ & $\begin{array}{c}\text { Mínimo } \\
\left(\mu \mathrm{g} / \mathrm{m}^{3} \mathrm{P}\right)\end{array}$ & $\begin{array}{c}\text { Máximo } \\
\left(\mu \mathrm{g} / \mathrm{m}^{3} \mathrm{P}\right)\end{array}$ & $\begin{array}{c}\mathrm{MGA} \\
\left(\mu \mathrm{g} / \mathrm{m}^{3} \mathrm{P}\right)\end{array}$ & $\mathrm{NE}^{* *}$ \\
\hline \hline PONTO - I & 60 & 17,00 & 258,04 & 68,23 & 01 \\
\hline PONTO - II & 54 & 23,72 & 443,28 & 83,08 & 06 \\
\hline \hline
\end{tabular}

\section{*MGA - Média Geométrica Anual $80 \mu \mathrm{g} / \mathrm{m}^{3}$ \\ ${ }^{* *} N E$ - Número de vezes excedentes ao padrão primário $240 \mathrm{~g} / \mathrm{m}^{3}$}

As Médias Aritméticas Anuais de Partículas Inaláveis - PI do período 20 de Junho de 2003 a 08 de Junho de 2004, encontram-se dentro do limite estabelecido pela Resolução CONAMA 03/90 através de concentração de Partículas Inaláveis - PI, para Padrão Primário de $\mathbf{5 0 m g} / \mathbf{m}^{3}$, nos pontos avaliados. As Médias Geométricas Anuais de Partículas Totais em Suspensão - PTS encontram-se dentro do limite estabelecido pela Resolução CONAMA 03/90 de concentração de Partículas Totais em Suspensão - PTS, para Padrão Primário de $80 \mathrm{mg} / \mathbf{m}^{3}$, no PONTO I e acima do limite no PONTO II.

As figuras $4 \mathrm{a} \mathrm{e} \mathrm{b}$ apresentam os resultados de médias anuais de PI e PTS apresentando ainda dados de médias de precipitação mensal (em mm).

Pela análise da Tabela 1 e Figura 4 a, b é possível perceber vários fatores de interação que permitiram relacionar parâmetros técnicos adquiridos no monitoramento com os dados metereológicos fornecidos pelo INMET - Instituto Nacional de Meteorologia.

- Quanto ao monitoramento das partículas inaláveis - PI tanto no Ponto I quanto no Ponto II, os valores medidos não ultrapassaram o limite estabelecido por lei para um (01) dia/ano no período entre junho de 2003 e junho de 2004. Por outro lado, o monitoramento das partículas totais em suspensão - PTS indicam que o Ponto I apresentou condição inadequada em 01 (um) dia de avaliação ficando acima do limite estabelecido pela Resolução CONAMA 003/90, onde a concentração máxima diária de Partículas Totais em Suspensão - PTS, permitida para um dia no ano que é de $240 \mathrm{mg} / \mathrm{m}^{3}$. O PONTO II apresentou 05 (cinco) dias de condições inadequadas e 01 (um) dia como má a Qualidade do Ar na região avaliada.

- As médias anuais de partículas totais em suspensão e inaláveis são fortemente influenciados pelos níveis de precipitação. Nos meses de estiagem (seca) o material particulado teve aumento considerável da concentração das partículas no ar, levando os resultados a uma alta expressiva ou regular e inadequada qualidade do ar em alguns casos. Quando as coletas do monitoramento ocorreram no período das chuvas, os resultados encontram-se abaixo ou dentro dos limites de boa qualidade do ar. Tais dados podem ser comprovados pela Figura 4 a, b e Anexos 1 e 2 .

- Outro fator de grande relevância nos resultados foi a influência da direção de movimentação dos ventos. Segundo dados do INMET a movimentação predominante dos ventos ocorre no sentido sentido Sudeste/Noroeste. Os valores de concentrações de PI e PTS medidos no PONTO I são inferiores àqueles medidos no PONTO II. Além de ter possibilitado a instalação mais adequada dos equipamentos de avaliação o monitoramento da direção dos ventos fornecido pelo INMET, permitiu determinar que a área de entorno ao aterro mais prejudicada pela dispersão 
(a)

\section{RESULTADOS DAS MÉDIAS ANUAIS PARTICULAS INALAVEIS - PI}

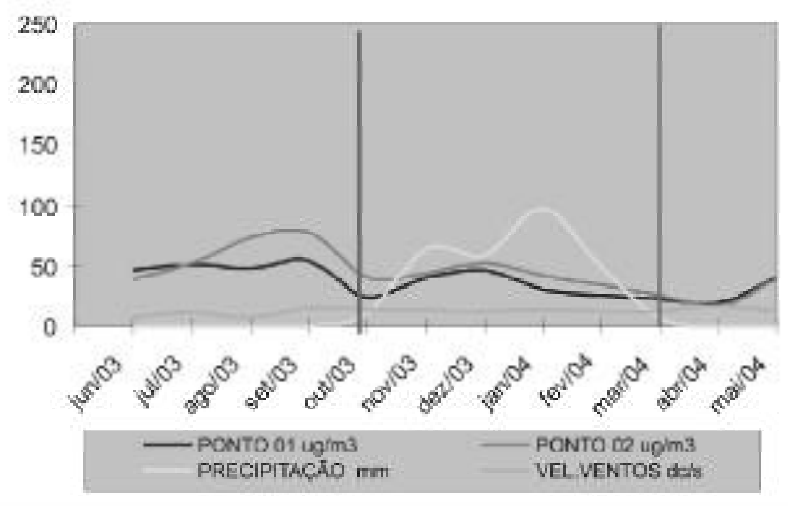

(b)

\section{RESULTADOS DAS MÉDIAS ANUAIS PARTÍCULAS TOTAIS EM SUSPENSÃO - PTS}

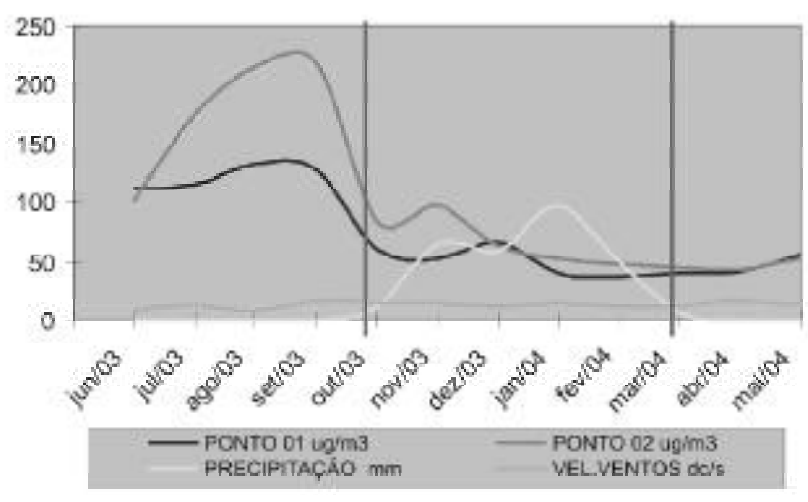

Figura 4 - Gráficos representativos dos resultados dos monitoramentos para PI(a) e PTS(b). O traço na vertical indica a separação do período chuvoso do período de estiagem.

das partículas, detectadas no monitoramento atmosférico é a região á noroeste do empreendimento.

- Por fim, a área de influência do Aterro Sanitário de Belo Horizonte contribui com o aumento do material particulado na atmosfera, pois os resultados obtidos à montante do aterro (Ponto I) foram expressivamente menores que aqueles obtidos no Ponto II, à jusante do aterro.

Os dados técnicos obtidos no monitoramento atualmente fazem parte dos históricos do Sistema de Limpeza Urbana da Prefeitura Municipal de Belo Horizonte, que os utilizou para a implantação das medidas mitigadoras já implantadas. A mesma atualmente mantém este controle em mais de cinco pontos utilizando os equipamentos $\mathrm{Hi}$-Vol e PM 10. O controle da emissão de partículas é feito utilizando caminhões-pipa, que molham as vias de movimentação dentro do aterro, principalmente as vias próximas à divisa entre o Aterro Sanitário e bairros do entorno sendo esta medida ampliada nos períodos de estiagem.

\section{AGRADECIMENTOS}

Os autores agradecem ao INSTITUTO NACIONAL DE METEOROLOGIA - INMET $\left(5^{\circ}\right.$ DISTRITO DE METEOROLOGIA - $5^{\circ}$ DISME SEÇÃO DE OBSERVAÇÃO E METEOROLOGIA APLICADA - SEOMA) pelos dados de precipitação diária, velocidade dos ventos e direção dos ventos no período de monitoramento deste trabalho.

\section{REFERÊNCIAS BIBLIOGRÁFICAS}

Almeida, I. T. 1999. A Poluição Atmosférica por Material Particulado na Mineração a céu aberto. Dissertação (Mestrado em Engenharia Mineral). Universidade Federal de São Paulo, USP, São Paulo. $186 \mathrm{p}$. 
Associação Brasileira de Normas Técnicas (ABNT). 1997. NBR 9547: Material Particulado em Suspensão no Ar Ambiente Determinação da concentração Total pelo Método do Amostrador de Grande Volume.

Associação Brasileira de Normas Técnicas (ABNT). 1987. NBR 80-100-140: Solo e Sedimentos de Corrente Peneiramento e Pulverização de Material em Malhas.

Associação Brasileira de Normas Técnicas (ABNT). 2002. NBR 6023: Informação e documentação: referências: elaboração. Rio de Janeiro.

Brandalise, L.A. 1999. Programa de Levantamentos Geológicos Básicos do Brasil. Belo Horizonte. Folha SE.23-Z-C-VI. Estado de Minas Gerais. Escala 1:100.000. CPRM. CD-ROM.

Brasil Resolução Conama 003/1990. Estabelece Padrões de Qualidade do Ar e Amplia o Número de Poluentes AtmosféricosPassíveis do Monitoramento e Controle. Coletânea de Legislação Ambiental. Disponível em: <http://www.pr.gov.br/iap>. Acesso em 08 de junho 2004.

Brasil Resolução Conama 008/1990. Estabelece Limites Máximos de Emissão de Poluentes do Ar a Nível Nacional. Coletânea de Legislação Ambiental. Disponível em: 〈http://www.pr.gov.br/iap〉. Acesso em 08 de junho 2004.

CPRH . 1999. Companhia Pernambucana de Meio Ambiente. Qualidade do ar na Região Metropolitana do Recife - 1998. Recife: CPRH.

Dias, J. W. C. 2001. AGV-PTS Manual de Operação. Energética, Rio de Janeiro.
Sousa, H.A.; Roeser, H.M.P.T; Matos, A.T. 2002. Método e Técnica Aplicadas na Avaliação Ambiental do Aterro da BR-040 da Prefeitura Municipal de Belo Horizonte REM: R. Esc. Minas, Ouro Preto, 55(4): 291-300, out. dez. 2002

Jacomino, M.M.F.; Ribeiro, E.D.L.; Castro, L.F.A. 2002. Seleção de padrões de emissão atmosférica. Um estudo de caso para pequenas e médias empresas produtoras de ferro-Gusa do Estadod e Minas Gerais. Engenharia Sanitária e Ambiental, Vol. 7, No $(3,4)$ pp. 112-116.

United States Environmental Protection Agency. 1992. Reference Method for the Determination of Suspended Particulate Matter in the Atmosphere. High volume method. SL., 42. (Federal Register 40 CFR 50, Appendix B)

United States Environmental Protection Agency. 1992. Reference Method for the Determination of Particulate Matter as PM10 in the Atmosphere. High volume method. SL., 42. (Federal Register 40 CFR 50, Appendix J)

Noce, C.M. 1995. Geocronologia dos eventos magmáticos, sedimentares e metamórficos da Região do Quadrilátero Ferrífero, Minas Gerais. São Paulo: Instituto de Geociências, USP. (Tese de Doutoramento).

Silva, A.B., Carvalho, E.T., Fantinel, L.M., Romano, A.W., Viana, C.S Estudos geológicos, hidrogeológicos, geotécnicos e geoambientais integrados no Município de Belo Horizonte. Relatório Final. Belo Horizonte. Prefeitura Municipal de Belo Horizonte. UFMG/IGC/ FUNDEP, 1995. 150p.

Sistema de Limpeza Urbana - SLU, Prefeitura Municipal de Belo Horizonte, Boletim Informativo de Dezembro de 1994

Anexo 1 - Resultados do monitoramento da qualidade do ar do Ponto I, à montante do empreendimento.

\begin{tabular}{|c|c|c|c|c|c|c|c|}
\hline \multicolumn{8}{|c|}{ PONTO I - PI (Partículas Inaláveis) } \\
\hline COLETA & $1^{\mathrm{a}}$ & $2^{\mathrm{a}}$ & $3^{\mathrm{a}}$ & $4^{\mathrm{a}}$ & $5^{\mathrm{a}}$ & $6^{\mathrm{a}}$ & MÉDIA \\
\hline Jun/03 & 64,29 & 73,91 & & & & & 69,10 \\
\hline Jul/03 & 55,74 & 89,01 & 22,09 & 46,61 & 45,39 & & 51,77 \\
\hline Ago/03 & 23,93 & 86,50 & 46,26 & 38,79 & 46,30 & & 48,36 \\
\hline Set/03 & 44,96 & 30,99 & 30,55 & 35,83 & 131,81 & 46,96 & 53,52 \\
\hline Out/03 & 31,05 & 10,65 & 19,07 & 24,95 & 37,85 & & 24,71 \\
\hline Nov/03 & 45,16 & 53,78 & 33,68 & 36,88 & 32,08 & & 40,32 \\
\hline Dez/03 & 41,90 & 34,65 & 57,89 & 61,95 & 36,26 & & 46,53 \\
\hline Jan/04 & 27,35 & 27,64 & 24,25 & 41,26 & 32,93 & & 30,69 \\
\hline Fev/04 & 27,97 & 25,23 & 28,26 & 26,31 & 21,97 & & 25,95 \\
\hline Mar/04 & 8,87 & 24,71 & 34,78 & 23,51 & 22,65 & & 22,90 \\
\hline Abr/04 & 13,67 & 11,38 & 12,58 & 28,32 & 32,55 & & 19,70 \\
\hline Mai/04 & 30,66 & 40,67 & 39,64 & 40,90 & 50,22 & & 40,42 \\
\hline Jun/04 & 28,49 & 20,14 & & & & & 23,75 \\
\hline \multicolumn{7}{|c|}{ Média Aritmética Anual da Concentração $\left(\mu \mathrm{g} / \mathrm{m}^{3}\right)$ de Partículas Inaláveis } & 38,33 \\
\hline \multicolumn{8}{|c|}{ PONTO I-PTS (Partículas Totais em Suspensão) } \\
\hline COLETA & $1^{\mathrm{a}}$ & $2^{\mathrm{a}}$ & $3^{\mathbf{a}}$ & $4^{\mathrm{a}}$ & $5^{\mathrm{a}}$ & $6^{\mathrm{a}}$ & MÉDIA \\
\hline Jun/03 & 161,60 & 177,19 & & & & & 169,22 \\
\hline Jul/03 & 66,80 & 258,04 & 104,08 & 119,72 & 94,45 & & 115,20 \\
\hline Ago/03 & 102,49 & 200,52 & 117,72 & 116,00 & 140,01 & & 131,48 \\
\hline Set/03 & 52,88 & 139,33 & 120,30 & 197,16 & 183,83 & 129,34 & 126,79 \\
\hline Out/03 & 116,60 & 17,00 & 97,19 & 55,99 & 75,67 & & 60,58 \\
\hline Nov/03 & 54,81 & 62,92 & 58,33 & 51,14 & 37,47 & & 52,14 \\
\hline Dez/03 & 75,51 & 42,97 & 69,29 & 100,54 & 62,52 & & 67,61 \\
\hline Jan/04 & 37,49 & 28,55 & 50,98 & 41,93 & 41,06 & & 39,32 \\
\hline Fev/04 & 50,69 & 30,49 & 36,97 & 31,32 & 36,20 & & 36,50 \\
\hline Mar/04 & 19,66 & 49,73 & 67,35 & 40,27 & 38,61 & & 40,00 \\
\hline Abr/04 & 46,66 & 24,61 & 42,65 & 60,70 & 43,06 & & 41,83 \\
\hline Mai/04 & 46,26 & 49,15 & 58,49 & 57,16 & 75,11 & & 56,41 \\
\hline Jun/04 & 65,63 & 83,22 & & & & & 55,17 \\
\hline Média & métrica & Ida Cond & גção ( $\mu$ c & P & em & são & 68,23 \\
\hline
\end{tabular}


Anexo 2 - Resultados do monitoramento da qualidade do ar do Ponto II à jusante do empreendimento

\begin{tabular}{|c|c|c|c|c|c|c|c|}
\hline \multicolumn{8}{|c|}{ PONTO II - PI (Partículas Inaláveis) } \\
\hline COLETA & $1^{\mathrm{a}}$ & $2^{\mathrm{a}}$ & $3 \mathbf{a}$ & 4a & 5 & $6 \mathrm{a}$ & MÉDIA \\
\hline Jun/03 & 57,30 & 47,16 & & & & & 52,23 \\
\hline Jul/03 & 117,35 & 36,79 & 52,92 & 30,83 & 24,45 & & 52,47 \\
\hline Ago/03 & 67,80 & 75,36 & 47,63 & 79,11 & 96,70 & & 73,32 \\
\hline Set/03 & 23,58 & & 123,89 & 59,92 & 124,12 & 58,68 & 78,04 \\
\hline Out/03 & 42,98 & 17,11 & 58,08 & 27,84 & 56,59 & & 40,52 \\
\hline Nov/03 & 53,36 & 48,04 & 29,82 & & & & 43,74 \\
\hline Dez/03 & & & 33,94 & 94,74 & 29,24 & & 52,64 \\
\hline Jan/04 & 30,59 & 39,08 & 44,53 & 49,34 & 46,87 & & 42,08 \\
\hline Fev/04 & 40,97 & 22,51 & 39,04 & 35,75 & & & 34,57 \\
\hline Mar/04 & 17,00 & 42,08 & 38,39 & 16,94 & 16,65 & & 26,21 \\
\hline Abr/04 & 9,85 & 10,78 & 12,37 & 27,90 & 20,28 & & 16,24 \\
\hline Mai/04 & 25,03 & 39,45 & 40,91 & 40,62 & 47,18 & & 38,64 \\
\hline Jun/04 & 31,77 & 23,03 & & & & & 27,40 \\
\hline \multicolumn{7}{|c|}{ Média Aritmética Anual da Concentração $\left(\mu \mathrm{g} / \mathrm{m}^{3}\right)$ de Partículas Inaláveis } & 44,47 \\
\hline \multicolumn{8}{|c|}{ PONTO II - PTS (Partículas Totais em Suspensão) } \\
\hline COLETA & $1^{\mathrm{a}}$ & $2^{\mathrm{a}}$ & 3 & $4^{\mathrm{a}}$ & 5 & $6^{\mathrm{a}}$ & MÉDIA \\
\hline Jun/03 & 197,71 & 103,38 & & & & & 142,97 \\
\hline Jul/03 & 229,91 & 142,01 & 241,45 & 145,30 & 145,83 & & 175,62 \\
\hline Ago/03 & 347,82 & 111,26 & 190,42 & 183,12 & 346,16 & & 215,72 \\
\hline Set/03 & 127,27 & 249,00 & 443,28 & 147,13 & 266,00 & 191,85 & 217,37 \\
\hline Out/03 & 176,24 & 24,97 & 148,75 & 64,18 & 99,95 & & 84,07 \\
\hline Nov/03 & 109,07 & 94,58 & 90,27 & & & & 97,65 \\
\hline Dez/03 & & & 52,99 & 106,68 & 46,46 & & 64,04 \\
\hline Jan/04 & 40,62 & 44,91 & 49,03 & 62,78 & 68,87 & & 52,18 \\
\hline $\mathrm{Fev} / 04$ & 62,30 & 30,94 & 57,43 & 44,32 & & & 47,06 \\
\hline Mar/04 & 29,96 & 110,67 & 76,53 & 30,47 & 23,72 & & 44,94 \\
\hline Abr/04 & 51,80 & 37,23 & 34,86 & 59,45 & 36,97 & & 43,04 \\
\hline Mai/04 & 43,36 & 53,66 & 43,39 & 51,79 & 81,45 & & 53,19 \\
\hline Jun/04 & 46,38 & 71,05 & & & & & 57,40 \\
\hline \multicolumn{7}{|c|}{ Média Geométrica Anual da Concentração $\left(\mu \mathrm{g} / \mathrm{m}^{3}\right)$ de Part. Totais em Suspensão } & 83,08 \\
\hline
\end{tabular}

